\title{
Isolation and Characterization of Pectin from the Ripe Fruit Peels of Jackfruit (Artocarpus heterophyllus Lam.)
}

\author{
Erna C. Arollado, ${ }^{1,2}$ Kerstin Mariae G.Ponsaran ${ }^{2}$ and Monet M. Loquias ${ }^{1}$ \\ ${ }^{1}$ College of Pharmacy, University of the Philippines Manila \\ ${ }^{2}$ Institute of Pharmaceutical Sciences, National Institutes of Health, University of the Philippines Manila
}

\begin{abstract}
Background and Objective. Pectin is a complex polysaccharide which is commonly used as a gelling agent for food preparations and pharmaceutical formulations. Currently, the Philippines imports $100 \%$ of its pectin requirement from other countries which adds to the cost of products that utilizes pectin. Hence, the aim of this study was to isolate and characterize pectin from ripe jackfruit peels.
\end{abstract}

Materials and Methods. Peels of ripe jackfruit (Artocarpus heterophyllus Lam.) were subjected to digestion with water and sulfuric acid at $90^{\circ} \mathrm{C}$ then purified using alcohol and acetone. The isolated material from the peels was subjected to pectin identification tests using the methods from the US Pharmacopeia (USP). To further characterize the isolate, the methoxy and anhydrouronic acid contents, degree of esterification, functional groups (through FT-IR), ash content, and swelling index were determined.

Results. Ripe jackfruit peels yielded $5.74 \%$ of brown-colored pectin which was verified using the US Pharmacopeia identification tests for pectin. The methoxy and anhydrouronic acid contents were found to be $4.05 \%$ and $1.77 \%$, respectively, with results comparable with the standard pectin $(p<0.05)$. The peel's pectin has a degree of esterification of $26.34,1.77 \%$ ash content, and swelling index of 9.09. FT-IR analysis of isolated pectin revealed functional groups identical to that of the standard pectin.

Conclusion. Pectin from the ripe jackfruit peels is reported to be a potential source of pharmaceutical grade pectin. However, the AUA content and methoxy content of the isolated pectin did not meet the USP specification. Thus, the authors recommend that future investigators must optimize the isolation procedure to obtain pectin which meets the specification of USP.

Key Words: Artocarpus heterophyllus Lam., jackfruit peels, low-methoxy pectin, pectin

\section{INTRODUCTION}

Corresponding Author: Erna C. Arollado, RPh, MSc, PhD Institute of Pharmaceutical Sciences

National Institutes of Health

University of the Philippines Manila,

Pedro Gil Street, Ermita, Manila 1000, Philippines

Telephone: +632 5772001

E-mail: ernaarollado@gmail.com
Pectin is a complex anionic heteropolysaccharide composed of repeating units of (1-4)-linked $\alpha$-D-galacturonic acid, interrupted by L-rhamnose residues with side chains of neutral sugars. ${ }^{1,2}$ It is located not just in the primary cell walls but also in the middle lamellas between plant cells ${ }^{3}$ wherein it contributes to the firmness and structure of plant tissue. ${ }^{4}$ It is usually obtained from the by-products of fruit juice, cider, and wine preparation. Common sources of pectin are citrus fruits such as lemon, orange and grapefruit, and apple pomace.

According to the International Pectin Producers Association (IPPA), ${ }^{5}$ different types of commercially available pectin are widely sold according to their application. Rapid set pectin is traditionally used for making jams and marmalades. Slow set pectin is commonly used in jellies and 
in some food preserves which uses vacuum cooking at lower temperature. The low methyl ester and amidated pectin are widely used in lower sugar products, reduced sugar preserves, fruit preparations for yogurts, dessert gels, and toppings or savory applications such as sauces and marinades.

In addition, pectin also has reported medicinal properties. It is reported to relieve constipation and diarrhea, and control hemorrhage or local bleeding by shortening the coagulation time of drawn blood. ${ }^{6}$ In throat lozenges, pectin serves as demulcent. Furthermore, the pharmaceutical industry utilizes pectin as a binder excipient in tablet formulations, as a gelling agent in hydrogels, and in wound dressings. ${ }^{7}$

Based on the diverse pectin utilization, it is a good investment to have local manufacture of pectin which uses local fruits like jackfruit as a source since according to the data given by PhilMech in 2013, the Philippines was importing $100 \%$ of its pectin requirement which cost around Php 27,000 per kilogram. Therefore, this study isolated and characterized pectin from the ripe jackfruit peel.

\section{MATERIALS AND METHODS}

\section{Plant collection}

Fresh ripe fruit of jackfruit was obtained in a local market in Manila City, Philippines. The plant material was identified and authenticated as Artocarpus heteropyllus Lam. at the Botany Division of National Museum in Manila, Philippines.

\section{Sample storage}

Ripe jackfruit peels were removed and rinsed with water and subjected to a blanching treatment, which resulted to enzymatic inactivation. This was done by immersing the peels in water at a temperature of $97^{\circ} \mathrm{C}$ for $3 \mathrm{~min}$, then, transferred to another water bath at room temperature and maintained for $15 \mathrm{~min}$. Subsequently, the peels were dried in an aircirculated oven at $50^{\circ} \mathrm{C}$ until a constant weight was obtained. The dried samples were then milled and passed through a sieve mesh 60 . The resulting powdered sample is referred to as flour. The sample flours were packaged in a polyethylene bag and were stored in a freezer $\left(-15 \pm 2^{\circ} \mathrm{C}\right)$.

\section{Isolation and purification of pectin}

The modified procedure of Cantoria $(1977)^{8}$ was used in the study. Fifty grams of the sample flour was accurately weighed and transferred to a $1000 \mathrm{~mL}$ beaker. Four hundred $\mathrm{mL}$ distilled water and $6 \mathrm{~mL} 3 \mathrm{~N}$ sulfuric acid were added. The mixture was then heated to $90^{\circ} \mathrm{C}$ with occasional stirring. Digestion was continued at 85 to $90^{\circ} \mathrm{C}$ for 30 min. The mixture was filtered through cheesecloth using a Buchner funnel. The digestion was repeated for another 15 $\mathrm{min}$. The filtrate from the first and second digestion were then combined and placed overnight in a refrigerator at $4^{\circ} \mathrm{C}$, after which, floatation of the pectin was done by adding ethyl alcohol ( $55 \%$ by volume) to the cooled filtrate and the mixture was allowed to stand for $30 \mathrm{~min}$. The isolated pectin was separated by filtration. This was purified by immersing it overnight in ethyl alcohol followed by washing with few volumes of acetone. The purified pectin was then air-dried, and the percentage yield was computed.

\section{Identification of pectin}

Ripe jackfruit peels pectin was verified using the methods A, B, C, and D discussed in pectin monograph from US Pharmacopeia 32. Results were compared with standard pectin from apple pomace (Sigma-Aldrich). Tests were done in triplicate.

\section{Method A}

One gram of the obtained pectin was heated with $9 \mathrm{~mL}$ of water on a steam bath until a solution was formed. Water lost on evaporation was replaced until it formed a stiff gel on cooling.

\section{Method B}

One gram of the isolated pectin obtained was dissolved in $100 \mathrm{~mL}$ of water. An equal volume of alcohol was added to this solution. Presence of a translucent, gelatinous precipitate distinguishes pectin from other gums.

\section{Method C}

From a solution of pectin in water (1 in 100), an aliquot of $5 \mathrm{~mL}$ was taken. One $\mathrm{mL}$ of $2 \mathrm{~N}$ sodium hydroxide was added and allowed to stand at room temperature for 15 min. Formation of a gel or a semi-gel distinguishes pectin from tragacanth.

\section{Method D}

The gel from Method C was acidified with 3N hydrochloric acid and shaken. The positive result for pectin is indicated by the formation of a voluminous, colorless, gelatinous precipitate which, when boiled becomes white and flocculent owing to the formation of the pectic acid.

\section{Characterization of pectin}

The isolated pectin was characterized based on the methodology performed by Virk and Sogi $(2004)^{9}$ which includes assays on equivalent weight, methoxyl content, alkalinity of ash, anhydrouronic acid content, degree of esterification, and swelling index. Results were compared with standard pectin from apple pomace (Sigma-Aldrich). Tests were done in triplicate.

\section{Equivalent weight}

The equivalent weight was obtained by weighing $0.5 \mathrm{~g}$ of the pectin sample and $1.0 \mathrm{~g}$ sodium chloride $(\mathrm{NaCl})$ in a conical flask. Ethanol $(5 \mathrm{~mL})$ and carbon dioxide-free water $(100 \mathrm{~mL})$ were added to the flask. The flask was shaken until the pectin was dissolved completely. Three to six drops of phenol red indicator were added and the solution was titrated against the standard $0.1 \mathrm{M}$ sodium hydroxide $(\mathrm{NaOH})$ 
until the color of the indicator changed ( $\mathrm{pH} 7.5$ ) to pink and persisted for at least $30 \mathrm{sec}$. The equivalent weight was computed using the formula below:

$$
\text { Equivalent weight }=\frac{\text { Wt. of sample }(\mathrm{g}) \times 1000}{\text { Vol. of alkali }(\mathrm{mL}) \times \text { normality of alkali }}
$$

\section{Assay for methoxy content}

To the neutral solution titrated for the equivalent weight containing $0.5 \mathrm{~g}$ of pectic substance, $25 \mathrm{~mL}$ of $0.25 \mathrm{~N} \mathrm{NaOH}$ was added, shaken thoroughly, and allowed to stand for 30 min at room temperature in a stoppered flask. Hydrochloric acid $(25 \mathrm{~mL}, 0.25 \mathrm{~N})$ was added and titrated with $0.1 \mathrm{~N}$ $\mathrm{NaOH}$ to the same endpoint as before. The methoxy content was calculated using the equation below:

$$
\begin{aligned}
& \text { Methoxy } \\
& \text { content (\%) }
\end{aligned}=\frac{\text { Vol. of alkali }(\mathrm{mL}) \times \text { normality of alkali x } 31 \times 100}{\text { Wt. of sample }(\mathrm{g}) \times 1000}
$$

\section{Alkalinity of ash}

The sample was ashed and $\mathrm{HCl}(0.1 \mathrm{~N}, 25 \mathrm{~mL})$ was added. The mixture was heated to boil, cooled, and titrated against standard $0.1 \mathrm{~N} \mathrm{NaOH}$ using phenolphthalein as indicator. Blank titration with $\mathrm{HCl}(0.1 \mathrm{~N}, 25 \mathrm{~mL})$ was also carried out. The alkalinity of the ash was computed using the formula below:

$$
\text { Alkalinity }(\%)=\frac{(\text { Blank }- \text { titre }) \times \text { normality of alkali x } 60 \times 100}{\text { Wt. of ash }(g) \times 1000}
$$

\section{Anhydrouronic acid content}

The alkali milliequivalents from the equivalent weight, methoxyl content, and alkalinity of ash were taken to calculate the anhydrouronic acid (AUA) content.

$$
\text { AUA }(\%)=\frac{\begin{array}{c}
176 \text { (m.e. for free acid + m.e. for saponification } \\
+ \text { m.e. for titrable ash) } \times 100
\end{array}}{\text { Wt. of sample }(\mathrm{g}) \times 1000}
$$

\section{Degree of esterification}

The degree of esterification was calculated from methoxy and anhydrouronic acid content using the expression given below:

$$
\text { Degree of esterification }=\frac{176 \times \text { methoxyl content }(\%) \times 100}{31 \times \text { anhydrouronic acid }(\%)}
$$

\section{Determination of swelling index}

One gram of the pectin obtained was placed in a covered tube with $10 \mathrm{~mL}$ distilled water. This mixture was shaken and allowed to stand for 1 hour. After one hour, the remaining water in the tube was discarded and the weight increase of the suspending agent was noted. The swelling index was computed through the equation:

$$
\text { Swelling index }=\frac{W 2-W 1}{W 1}
$$

Where:

W1 $=$ Weight of the suspending agent at time 0 W2 $=$ Weight of the suspending agent after 1 hour

\section{Fourier transform infrared (FT-IR) analysis}

The isolated and purified pectin was submitted to the Analytical Services Laboratory of the Institute of Chemistry at the University of the Philippines Diliman, Quezon City for FT-IR analysis to check if both standard pectin and pectin from ripe jackfruit peels have comparable functional groups. The molecular composition of each sample was examined using Shimadzu Prestige 21 FTIR spectrophotometer. The FTIR scan was acquired using attenuated total reflectance (Miracle ATR, single reflectance, Pike Technologies).

\section{Statistical treatment}

The data gathered were expressed as Mean \pm Standard Error and analyzed using one-way ANOVA. SPSS 16.0 was the statistical software used.

\section{RESULTS}

The ripe jackfruit peels yielded $5.74 \%$ of brown pectin which obtained positive results on the US Pharmacopeia identification tests for pectin (Table 1). Table 2 shows the

\begin{tabular}{|c|c|c|c|c|c|c|}
\hline \multirow[b]{2}{*}{ Sample } & \multirow{2}{*}{$\begin{array}{c}\text { Method A } \\
\text { Formation of } \\
\text { stiff gel }\end{array}$} & \multirow{2}{*}{$\begin{array}{c}\text { Method B } \\
\text { Translucent, } \\
\text { gelatinous } \\
\text { precipitate }\end{array}$} & \multirow{2}{*}{$\begin{array}{c}\text { Method C } \\
\begin{array}{c}\text { Gel or semigel } \\
\text { formation }\end{array}\end{array}$} & \multicolumn{3}{|c|}{ Method D } \\
\hline & & & & Voluminous & Colorless & $\begin{array}{c}\text { White and flocculent } \\
\text { when boiled }\end{array}$ \\
\hline Standard pectin & + & + & + & + & + & + \\
\hline A. heterophyllus & + & + & + & + & Light brown & Light brown and flocculent \\
\hline
\end{tabular}
summary of the results for the characterization of pectin. The swelling index of the isolated pectin was almost the same as that of the standard pectin. The standard pectin and the pectin from ripe jackfruit peels were both classified as lowmethoxy pectin based on their degree of esterification. The methoxy, anhydrouronic acid, and ash content of the pectin

Table 1. USP identification tests for pectin

Table 2. Physicochemical characteristics of ripe jackfruit peel pectin

\begin{tabular}{ccccc} 
Sample & Methoxyl content & Ash content (\%) & $\begin{array}{c}\text { Anhydrouronic acid } \\
\text { content (\%) }\end{array}$ & $\begin{array}{c}\text { Degree of } \\
\text { esterification }\end{array}$ \\
Standard & $7.57 \pm 0.60$ & $2.10 \pm 1.91$ & $91.60 \pm 0.80$ & $46.92 \pm 3.678$ \\
A. heterophyllus & $4.05 \pm 38$ & $1.77 \pm 0.90$ & $87.02 \pm 0.68$ & $26.34 \pm 0.65$ \\
\hline
\end{tabular}



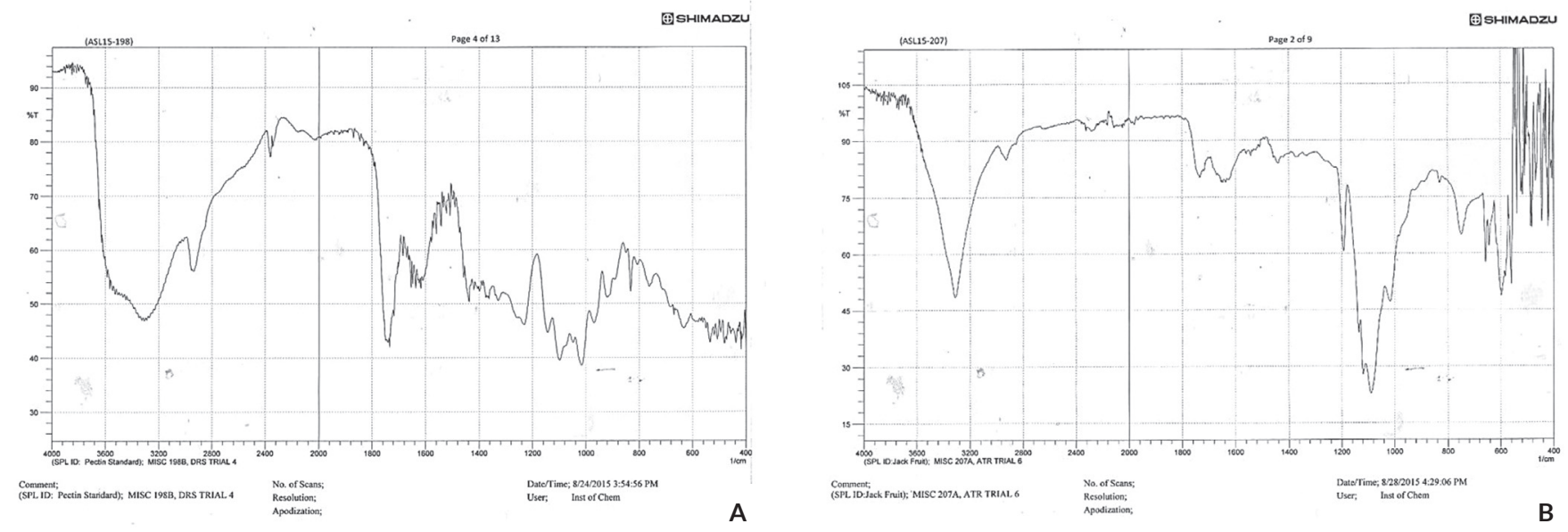

Figure 1. FT-IR scans. (A) Standard pectin, (B) Ripe jackfruit peel pectin.

from the fruit peel were found to be 4.05, 87.02, and 1.77, respectively which was comparable to that of the standard pectin $(p<0.05)$.

In the FT-IR analysis, typical characteristic peaks of pectin were observed including the frequencies which correspond to $\mathrm{O}-\mathrm{H}$ stretching of alcohols, ester carbonyl, carboxylate ion, pyranose ring, $\mathrm{C}-\mathrm{O}$ dilatation, and $-\mathrm{CH} 3$ antisymmetric deformation or the $-\mathrm{CH} 2-$ symmetric deformation.

In Figure 1, the FT-IR scan shows absorption peaks around $3600-3000 \mathrm{~cm}^{-1}$ which indicated the $\mathrm{O}-\mathrm{H}$ stretching, $\sim 1748 \mathrm{~cm}^{-1}$ indicated the ester carbonyl $(\mathrm{C}=\mathrm{O})$ and $\sim 1636$ $\mathrm{cm}^{-1}$ indicated the carboxylate ion stretching.

\section{DISCUSSION}

Currently, the Philippines imports its pectin requirements from other countries. Thus, local production of pectin is very essential to bring down the cost of local pectin-based products, especially in medicines (e.g. tablet and hydrogels) and it can also open new trade avenues in pectin marketing. In this study, the ripe jackfruit peels were subjected to pectin isolation.

The physicochemical characteristics of the isolated pectin from the fruit peel were analyzed and compared to the standard pectin. Both pectin from the ripe jackfruit peels and standard were classified as low methoxy pectin based on its degree of esterification (DE) which was less than $50 \%$. High-methoxy pectin has DE of $>50 \%$. DE affects the gel formation of the pectin wherein the lower the $\mathrm{DE}$, the poorer its gel settling. Moreover, the methoxy content is an important factor in controlling the setting time and gel formation. ${ }^{10}$ The anhydrouronic acid (AUA) content, on the other hand, determines the galacturonic acid content that indicates the purity of pectin knowing that galacturonic acids are the backbone of pectin. Based on USP, specification of methoxy and AUA contents should not be less than $6.7 \%$ and
$74 \%$, respectively. The AUA content of fruit peel pectin was greater than the set limit. However, the methoxy content was found to be lower than the specified criteria. The isolation procedure done in this study, particularly, the blanching technique probably affected the methoxy content of the pectin. ${ }^{9}$ In addition, $\mathrm{pH}$ and temperature play an important role in pectin isolation. The $\mathrm{pH}$ is a factor in controlling the yield and pectin's side chain composition while temperature strongly affects the yield and molecular weight but has no significant effect on $\mathrm{DE} .{ }^{11}$ Unfortunately, the $\mathrm{pH}$ of the solvent used in extracting the pectin was not taken. In conclusion, pectin from ripe jackfruit peels was found to be a potential source of pharmaceutical grade pectin. The authors recommend to future investigators that the isolation procedure must be optimized and take into account the $\mathrm{pH}$ of the extracting solvent to obtain a good quality of pectin which meets the specification of pectin based on US Pharmacopeia.

\section{Acknowledgements}

We thank the National Research Council of the Philippines for funding this project.

\section{Statement of Authorship}

All authors have approved the final version submitted.

\section{Author Disclosure}

All the authors declared no conflicts of interest.

\section{Funding Source}

This paper was funded by the National Research Council of the Philippines.

\section{REFERENCES}

1. Ridley BL, O’Neil MA, Mohnen D. Phytochemistry. 2001; 57:929-67.

2. Mohare YS, Pratapwar AS, Sakarkar D, Sheikh A. Natural polymers used to sustain drug delivery systems. American Journal of Pharmaceutical Research. 2013;3(6):4238-61. 
3. Grassino AN, Halambek J, Djakovic S, Brncic SR, Dent M, Grabaric Z. Utilization of tomato peel waste from canning factory as a potential source for pectin production and application as tin corrosion inhibitor. Food Hydrocolloids. 2016; 52:265-74.

4. De Cindo B, Gabriele D, Lupi FR. Pectin: properties determination and uses. Encyclopedia of Food and Health. 2016;294-300.

5. International Pectin Producers Association [Online]. 2017. Available at http://www.ippa.info/applications_for_pectin.htm.

6. Srivastava P, Malviya R. Sources of pectin, extraction and its application in pharmaceutical industry: an overview. Indian Journal of Natural Products and Resources. 2011;2(1):10-8.

7. Kadajji VG, Betageri GV. Water soluble polymers for pharmaceutical applications. Polymers. 2011; 3:1972-2009.
8. Cantoria M. Pharmacognosy in action: the study of drugs of biological origin. Bicutan, Taguig City, Philippines: National Research Council of the Philippines; 1977.

9. Virk BS, Sogi DS. Extraction and characterization of pectin from apple (Malus pumila. $\mathrm{Cv}$ Amri) peel waste. International Journal of Food Properties. 2004;7(3): 693-703.

10. Constenla D, Lozano JE. Kinetic model of pectin demethylation. Latin American Applied Research. 2003; 33:91-6.

11. Methacanon P, Krongsin J, Gamonpilas C. Pomelo (Citrus maxima) pectin: effects of extraction parameters and its properties. Food Hydrocolloids. 2014; 35:383-91. 